\title{
The Biology of Plasmodium vivax
}

\author{
John H. Adams ${ }^{1}$ and Ivo Mueller ${ }^{2}$ \\ ${ }^{1}$ Center for Global Health and Infectious Diseases, Department of Global Health, University of South Florida, \\ Tampa, Florida 33612 \\ ${ }^{2}$ Population Health \& Immunity Division, Walter \& Eliza Hall Institute, Parkville, Victoria 3052, Australia \\ Correspondence: jadams3@health.usf.edu; ivomueller@fastmail.fm
}

\begin{abstract}
Plasmodium vivax is the second most prevalent cause of malaria worldwide and the leading cause of malaria outside of Africa. Although infections are seldom fatal clinical disease can be debilitating and imposes significant health and economic impacts on affected populations. Estimates of transmission and prevalence intensity can be problematic because many episodes of vivax originate from hypnozoite stages in the liver that have remained dormant from previous infections by an unknown mechanism. Lack of treatment options to clear hypnozoites and the ability to infect mosquitoes before disease symptoms present represent major challenges for control and eradication of vivax malaria. Compounding these challenges is the unique biology of $P$. vivax and limited progress in development of experimental research tools, thereby hindering development of new drugs and vaccines. Renewed emphasis on vivax malaria research is beginning to make progress in overcoming some of these challenges.
\end{abstract}

V vax malaria accounts for 14-80 million cases of clinical malaria each year with more than $70 \%$ of infections in Asia and the Americas (Mendis et al. 2001a; Price et al. 2007; WHO 2015). The last 10 years have seen a dramatic reduction in the burden of malaria, with many countries in the Asia-Pacific and the Americas with reductions of $>90 \%$ in the number of clinical cases (WHO 2015). As a consequence, 34 countries are actively attempting to eliminate malaria and the leaders of Central American and East Asian countries have declared their intention to eliminate malaria from their regions by 2025 and 2030, respectively (PAHO 2013; APLMA 2014). In parallel to this reduction in overall incidence, a pronounced shift in species composition has been

observed with Plasmodium vivax, now the predominant Plasmodium spp. in the vast majority of countries outside Africa, and is generally seen as the major obstacle to achieving malaria elimination in Asia and the Americas. The challenges in controlling and eliminating vivax malaria are likely to be related to the following aspects of P. vivax biology: (1) its ability to relapse from long-lasting, dormant liver stages (the hypnozoites) (White and Imwong 2012), and (2) its high transmission potential caused by early and continuous production of gametocytes, high infectivity to mosquitoes, and shorter development cycle in the vector host compared to other Plasmodium spp. (Mueller et al. 2009). These characteristics facilitate $P$. vivax transmission by seasonal mosquito vectors and at lower am-

Editors: Dyann F. Wirth and Pedro L. Alonso

Additional Perspectives on Malaria: Biology in the Era of Eradication available at www.perspectivesinmedicine.org

Copyright (C) 2017 Cold Spring Harbor Laboratory Press; all rights reserved; doi: 10.1101/cshperspect.a025585

Cite this article as Cold Spring Harb Perspect Med 2017;7:a025585 
bient environmental temperatures, thus extending the global distribution of $P$. vivax into temperate regions (Fig. 1) (Gething et al. 2011, 2012).

Although it has often been regarded as causing a benign self-limiting infection, there is increasing evidence that the overall burden, economic impact, and severity of disease from $P$. vivax have been underestimated (Price et al. 2007). Vivax malaria is known to incapacitate individuals of all ages resulting in repeated febrile episodes, severe anemia, respiratory distress, and, sometimes, poor outcomes in pregnancy. Increasing reports of clinical severity with complicated and lethal cases of vivax malaria, thus, challenge the perception of vivax malaria as benign (Anstey et al. 2012; Baird 2013). The increasingly widespread resistance to chloroquine, the primary frontline drug to treat vivax malaria (Baird et al. 1991; Ruebush et al. 2003; Teka et al. 2008; Ketema et al. 2009; Mohan and Maithani 2010; Rijken et al. 2011) represents an additional challenge to existing control and prevention programs for vivax malaria and highlights the critical need for more efforts toward development of new tools specifically targeting P. vivax.

Besides additional drugs targeting the dormant liver stages, the development of a vaccine against vivax malaria is especially important (Mueller et al. 2015). The rapid natural acquisition of immunity to P. vivax (Mueller et al. 2013) indicates that that the development of $P$. vivax vaccines should be feasible. Nevertheless, understanding correlates of protective immunity is as challenging for vivax malaria is it is for Plasmodium falciparum, because in most endemic areas, transmission is intermittent, with lack of sustained acquired immunity. Immune responses to the $P$. vivax vaccine candidate antigen, Duffy-binding protein (DBP), are often weak, short-lived, and biased toward strain-specific alleles (VanBuskirk et al. 2004; Ceravolo et al. 2009; Cole-Tobian et al. 2009; Chootong et al. 2010), which may be due, in part, to a high level degree of allelic diversity. Therefore, an effective vaccine against vivax malaria may face a greater challenge to have a substantial level of immunity against diverse strains.
In this article, we review the unique challenges associated with $P$. vivax experimental research, recent advances overcoming these obstacles, and breakthroughs needed to effectively deal with vivax malaria.

\section{THE UNIQUE BIOLOGY OF P. vivax}

Significant differences in the biology of $P$. vivax compared to $P$. falciparum are obvious by simple examination of a Giemsa-stained blood smear (Fig. 2) (Coatney et al. 1971). A typical parasitemia in vivax malaria is relatively low, which is attributed to restricted infection of only reticulocytes, often necessitating the use of thick smears to concentrate the blood for reliable diagnosis (Galinski and Barnwell 2008). Although not fixing the blood significantly increases sensitivity, it comes at the cost of retaining good morphology, which can present a challenge for parasite identification for nonexpert microscopists. Important for distinguishing different Plasmodium species is the observation of unique morphological features, such as the small dark granules in the reticulocyte cytoplasm, known as Schüffner's dots, representing caveola-vesicle complexes of parasite origin exported into the cytoplasm of the infected reticulocyte (Aikawa et al. 1975; Udagama et al. 1988), which increase in abundance as $P$. vivax develops. A second distinctive morphological feature for P. vivax is sexual-stage parasites have a round shape similar to the asexual stages. Finally, all P. vivax stages of blood-stage development can be observed in the peripheral blood.

The ability of $P$. vivax to remain in circulation is thought to be possible because of the increased plasticity of infected reticulocytes that is observed as the parasites develop, which is in contrast to the increased rigidity that occurs for P. falciparum-infected erythrocytes (Suwanarusk et al. 2004). Increased deformability is needed to periodically squeeze through the splenic chords and thereby evade removal from circulation (Handayani et al. 2009). Infected red blood cell (RBC) rigidity for P. falciparum is linked to cytoadherence and sequestration, but PfEMP1 knob proteins that are the key mediator of antigenic variant are absent in $P$. vivax. 
The Biology of Plasmodium vivax
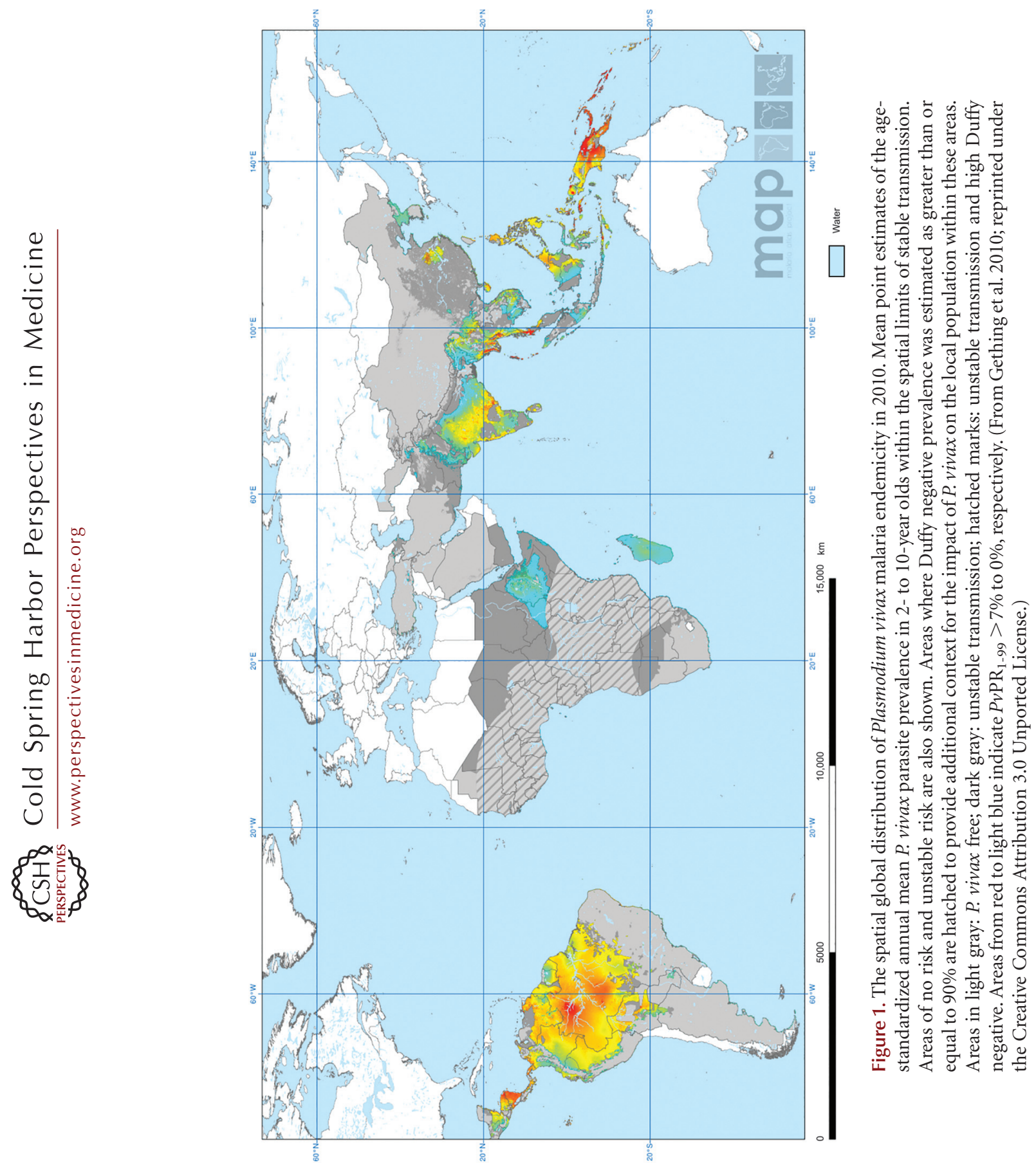
J.H. Adams and I. Mueller
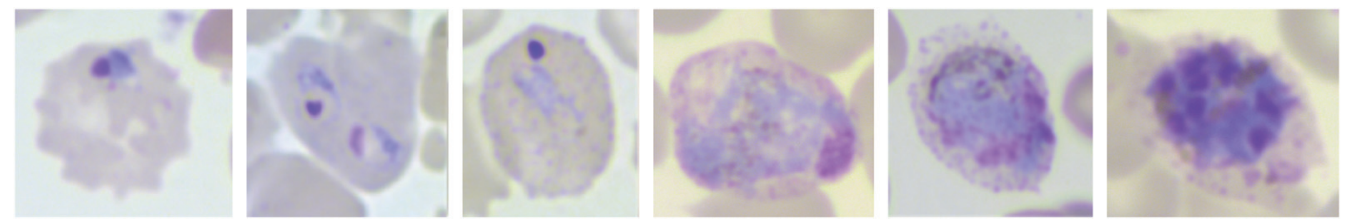

Figure 2. Light microscopic images of Giemsa-stained developmental stages of Plasmodium vivax during the blood-stage asexual cycle from early to late stages (left to right, respectively).

Antigenic variation originally described in the closely related vivax-like primate malaria Plasmodium knowlesi (Brown and Brown 1965) and is likely common to most, if not all, malaria parasites that are mediated by a large family of small surface variant antigens (Jemmely et al. 2010). In P. vivax, the VIR protein products of the vir multigene family are proposed to be the key molecule for antigenic variation in $P$. vivax (del Portillo et al. 2001). More recently, VIR proteins expressed on the reticulocyte surface are suggested to have a role mediating cytoadherence to endothelial cells and placenta, albeit much weaker than for P. falciparum (del Portillo et al. 2001; Fernandez-Becerra et al. 2005). Therefore, the lack of knobs and a strong sequestration mechanism does not mean that there is a lack of antigenic variation and sequestration, although cytoadherence to endothelium is less prevalent and possibly occurring only in more virulent infections (del Portillo et al. 2001; Fernandez-Becerra et al. 2005; Carvalho et al. 2010; Chotivanich et al. 2012). The lack of robust continuous culture methods have greatly hampered laboratory-based experimental studies of this and other unique biological properties of $P$. vivax.

In addition to their round morphology, P. vivax gametocytes are noteworthy for their very early appearance during the course of infection. In part, this may be caused by a rapid development time with gametocytes often detected within 3 days after the first asexual parasites are observed (Bousema and Drakeley 2011). In controlled experimental infections gametocytes appeared in the peripheral blood within 7 days of direct $P$. vivax sporozoite infection (Vallejo et al. 2016), indicating that in most natural infections mosquito transmission can occur before onset of clinical symptoms. Although early transmissibility can lead to rapid transmission with outbreaks spreading quickly, a side benefit attributed to this phenomenon is limiting the rapid spread of drug resistance for P. vivax. It is important to note that because transmission usually occurs before infections are treated, an effective transmission-blocking vaccine would help contain relapse infections that result from radical cure treatment failures (Douglas et al. 2013).

The key distinguishing feature of $P$. vivax biology is, however, its ability to form long-lasting liver stages, the hypnozoites (Krotoski et al. 1982). On entry into the liver, $P$. vivax sporozoites can take two distinct pathways. Some develop directly into liver-schizonts, which after 8 days, release merozoites to initiate the asexual cycle in the blood, although others, the hypnozoites, "arrest" their development beginning about the third day after infection (Coatney et al. 1971; Mikolajczak et al. 2015). Although hypnozoites are probably metabolically active, they do not divide and remain dormant for weeks if not months before reactivating. The frequency and timing of these relapses varies globally (White 2011), with the longest relapse periods present in temperate strains (Battle et al. 2014), indicating that relapse periodicity is under natural selection (White et al. 2016). The mechanisms underlying both commitment to dormancy and reactivation are poorly understood. However, it is increasingly clear that relapses from emerging such hypnozoites may contribute up to $80 \%$ of all $P$. vivax blood-stage infections (Betuela et al. 2012; Robinson et al. 2015). As there are no diagnostic tests that can diagnose dormant liver-stage infections, undetectable hypnozoite carriers are an important 
potential source of reintroduction of $P$. vivax and, if not treated appropriately, can cause new blood-stage infections months after the primary infection. Unfortunately, the only currently available drug to clear hypnozoites is primaquine, which can cause severe hemolysis in people with glucose 6-phosphate dehydrogenase (G6PD) deficiency (Baird et al. 2012). Given the lack of a cheap, reliable point-of-care G6PD test, many $P$. vivax patients do not currently receive adequate antihypnozoite treatment (Baird 2015).

\section{GENETIC DIVERSITY/POPULATION OF P. vivax}

Although its closest non-ape Plasmodium spp. are parasites of Southeast Asia monkeys, P. vivax is now thought to have originated in Africa with it closest relatives still circulating in African chimpanzee and gorilla populations (Liu et al. 2014). P. vivax shows a higher degree of genetic diversity and more global structure than $P$. falciparum. Comparative analyses revealed that $P$. vivax genomes show twice as much singlenucleotide polymorphism (SNP) diversity as P. falciparum and also have high microsatellite and gene family variability (Neafsey et al. 2012). Although $P$. falciparum microsatellite diversity is closely associated with regional levels of endemicity, $P$. vivax shows a high genetic diversity across all endemicities (Barry et al. 2015).

The global $P$. vivax population is nevertheless more strongly structured than that of $P$. falciparum. A comparative analyses of microsatellite diversity in a global panel of 841 P. vivax isolates showed very strong geographical structure with clearly distinct populations in South America, Africa and India, Southeast Asia, and the Southwest Pacific (Koepfli et al. 2015b). Similar global structure is also evident in sequences encoding for vaccine candidate antigens (Arnott et al. 2013) and has recently been confirmed using genome-wide SNPs (Hupalo et al. 2016; Pearson et al. 2016).

Contrary to the pronounced global structure, most studies found limited or no population structure at local or regional scale (Imwong et al. 2007; Getachew et al. 2015), even in areas where $P$. falciparum did show substantial population structure (Jennison et al. 2015; Noviyanti et al. 2015). This is likely to be caused by the generally higher genetic complexity of $P$. vivax infections (Barry et al. 2015), which increase the likelihood of genetic recombination and result in large effective population sizes. The exception to this pattern is found in the Americas, where pronounced local population structure is observed (Ferreira et al. 2007; Van den Eede et al. 2010; Delgado-Ratto et al. 2016), despite high continent-wide genetic diversity. This pattern is thought to be a reflection of both multiple introduction and more recent bottlenecks caused by intensified control.

Together, these patterns suggest a capacity for greater functional variation, a more distinct history of global colonization and a higher ability to maintain genetic diversity in the face of intensifying control efforts. More detailed studies of global and local $P$. vivax diversity are required to develop tools that will allow examination of the impact of control and elimination programs on the parasite gene pool. Of particular importance for local elimination would be to develop tools that allow for differentiation of locally acquired infections from imported $P$. vivax infections.

\section{THE ROLE OF ASYMPTOMATIC INFECTIONS}

Although $P$. vivax has a lower pyrogenic threshold than that of $P$. falciparum (Hemmer et al. 2006), asymptomatic $P$. vivax infections are very common at all levels of endemicity and often account for $90 \%-100 \%$ of all infections detected in cross-sectional surveys (Anstey et al. 2012). The vast majority of these P. vivax infections are of very low density, with submicroscopic infections accounting for $67 \%$ of all infections (Cheng et al. 2015). This is significantly higher than for P. falciparum in the same studies.

Several factors are thought to contribute to this very high rate of asymptomatic infections. Most importantly, clinical immunity to $P$. vivax infections is acquired rapidly. When malaria therapy patients were experimentally infected with $P$. vivax, effective clinical immunity, even 
against heterologous challenge, was often attained after as few as one to five $P$. vivax infections (Mueller et al. 2013; Snounou and Perignon 2013). Under natural exposure, clinical immunity to $P$. vivax is also acquired significantly more rapidly than to $P$. falciparum, both in high transmission settings such as $\mathrm{Pa}$ pua New Guinea, where the incidence of P. vivax malaria starts declining in the second year of life (Lin et al. 2010) and clinical disease is virtually absent in children $>5$ years, although $P$. falciparum episodes are common in primary school children (Michon et al. 2007), as well as in lower transmission settings such as Thailand (Phimpraphi et al. 2008), Sri Lanka (Mendis et al. 2001b), and Vanuatu (Maitland et al. 1996). With little evidence for naturally acquired immunity against (preeythrocytic) infections (Mueller et al. 2013), these patterns are indicative that, even in low transmission settings, semi-immune individuals develop effective blood-stage immunity characterized by a very good control of blood-stage parasitemia, which results in significant numbers of submicroscopic infections. The main driver for this rapid acquisition of immunity is the higher force of infections (Koepfli et al. 2013), caused largely by genetically distinct but related relapses (Bright et al. 2014) that account for up to $80 \%$ of all P. vivax blood-stage infections (Robinson et al. 2015).

The role of these asymptomatic infections in maintaining $P$. vivax transmission is not yet well understood. Most, if not all, of these asymptomatic infections produce gametocytes (Wampfler et al. 2013; Barbosa et al. 2014) with gametocyte densities closely correlated with overall parasitemia levels and thus at low levels (Koepfli et al. 2015a). Nevertheless, the asymptomatic cases are infectious to anopheline vectors, albeit at a substantially lower level than clinical cases (Pethleart et al. 2004; Alves et al. 2005), and may contribute substantially to maintaining $P$. vivax transmission given the high prevalence of the "silent" infections.

These asymptomatic infections may thus be a major impediment to the elimination of $P$. vivax malaria as they may not be efficiently cleared unless specifically targeted with active case detection and/or mass drug administration. Such a strategy is logistically challenging and would again require treating large numbers of individuals with asymptomatic infections, even those without detected blood-stage infections, with primaquine to clear the hypnozoite reservoir.

\section{ADVANCES IN ENABLING TECHNOLOGIES TO SUPPORT $P$. vivax RESEARCH}

The unique biology of $P$. vivax has presented major challenges for applying modern approaches in fundamental and translational research. In particular, the blood-stage requirement to infect reticulocytes and the hypnozoite liver stage have been difficult obstacles to overcome for laboratory-based research studies, thereby limiting most research efforts to using $P$. vivax from clinical isolates or nonhuman primate infections. In recent years, greater efforts from multiple laboratories have begun to provide new approaches to create more useful enabling technologies for research studies on the liver stages (Dembele et al. 2011; March et al. 2013; Mikolajczak et al. 2015). Unfortunately, similar success for developing a robust continuous culture system for blood-stage parasites has not been as successful with capabilities being limited primarily for short-term assays (Russell et al. 2011; Noulin et al. 2013; Roobsoong et al. 2015).

Because reticulocytes rapidly develop to mature erythrocytes at $37^{\circ} \mathrm{C}$, a reticulocyte's half-life is shorter than the blood-stage asexual developmental cycle time. Therefore, reticulocytes must be replenished as each new generation matures or there is nothing for the parasites to infect. An important strategy to overcome the reticulocyte problem was exemplified in the Golenda study (Golenda et al. 1997). This 19-yearold study from the Walter Reed Army Institute of Research remains the gold standard for sustained growth of in vitro blood-stage culture of P. vivax. In the Golenda study, blood-stage parasites were grown for six to eight asexual cycles using an inventive, but complex labor-intensive culturing protocol not easily replicated. The success of the Golenda study was likely because 
of a combination of variables that included use of the primate-adapted Chesson strain, obtaining reticulocytes from hemochromatosis patients undergoing traditional bloodletting treatments, which induces a reticulocytemia, and differential centrifugation methods for reticulocyte enrichment. Other important handling features of the protocol included exposure of the static cultures to intermittent agitation along with periodic addition of fresh reticulocytes. Of these variables, many subsequent studies identified the critical limiting factor for $P$. vivax blood-stage culture to be sustaining reticulocyte levels. Consequently, studies now include regular addition of relatively pure reticulocyte preparations so as to not dilute the culture with mature erythrocytes that cannot be invaded by $P$. vivax.

Traditional sources of reticulocytes to support $P$. vivax culture for most researchers have been placenta cord blood and adult peripheral blood, which are both readily available (Noulin et al. 2013). In both cases, reticulocytes constitute a subset of the total erythroid cell population and must be enriched (Udomsangpetch et al. 2007; Kumar et al. 2015). Over time, protocols have evolved to enable enrichment of nearly pure populations of reticulocytes from both of these traditional sources to overcome a historical limitation of attempts to establish $P$. vivax blood-stage cultures. Parallel to improvements in traditional approaches for enriching reticulocytes were the improvements and lowered costs in the hematopoietic stem cell (HSC) ex vivo production methods for creating reticulocytes (Douay and Giarratana 2005; Giarratana et al. 2005). These HSC reticulocytes have provided a third source, which also revealed the capacity of $P$. vivax to infected nucleated erythroid progenitor cells (Panichakul et al. 2007; Noulin et al. 2014). In addition, ex vivo reticulocytes produced from HSC can be experimentally manipulated to tease apart specific molecular interactions required for parasites infection (Crosnier et al. 2011; Egan et al. 2015). Despite being able to sustain abundant reticulocytes in vitro, a concomitant success in maintaining continuous long-term $P$. vivax culture has not been achieved yet, indicating factors beyond just reticulocytes are required to sustain parasites in vitro (Martin-Jaular et al. 2013; Roobsoong et al. 2015). Nonetheless, the value of studies reliant on traditional sources of $P$. vivax have improved considerably for support of fundamental and translational research (Price et al. 2010; Rijken et al. 2011; Marfurt et al. 2012; Lee et al. 2014; Malleret et al. 2015; Cho et al. 2016).

The basic capability to study complete in vitro development of $P$. vivax, $P$. falciparum, and other malaria parasites with primary hepatocytes and hepatocytoma cells has been established for many years (Mazier et al. 1984; Sattabongkot et al. 2006). With the increased awareness of the force of infection in vivax malaria caused by relapse (Betuela et al. 2012; Robinson et al. 2015), along with emergence of chloroquine resistance in many endemic regions (Baird et al. 1991; Ruebush et al. 2003; Teka et al. 2008; Ketema et al. 2009; Mohan and Maithani 2010; Rijken et al. 2011), there has been a renewed effort to develop higher throughput, more efficient, and longer duration systems for liver- stage studies, especially of hypnozoites (Wells et al. 2010; Campo et al. 2015). These efforts to improve capabilities for laboratory-based studies of the liver stages are yielding exciting results. Multiple new experimental platforms have emerged permitting researchers access to this least studied phase of $P$. vivax and human malaria parasites. Improvements in modified culture devices for in vitro enhancement of primary cell properties have progressed greatly to provide stability of viable primary human hepatocytes enhancing their potential use for malaria research (Dembele et al. 2011; March et al. 2013; Dembele et al. 2014; Maher et al. 2014; $\mathrm{Ng}$ et al. 2015). However, so far, the most significant innovations established are in vivo humanized mouse models (Shultz et al. 2007; Peltz 2013). These human liver-chimeric mice support complete liver-stage development, including persisting hypnozoites, of P. vivax and Plasmodium ovale (Mikolajczak et al. 2015; Soulard et al. 2015). These mouse models offer the potential to explore liver-stage biology and evaluate antimalarial candidates, in ways that were previously only possible 
J.H. Adams and I. Mueller

through the use of primate models (Coatney et al. 1971).

\section{CONCLUDING REMARKS}

If the ambitious goals for the elimination of malaria are to be achieved, new tools specifically targeting $P$. vivax will be required. Accelerating the development of new drugs and vaccines will require both a better understanding of the unique $P$. vivax biology and the development of key research tools such as in vitro culture and in vivo models. Although significant progress has been made, many challenges remain.

Addressing these will require novel interdisciplinary research approaches that bridge from the field to the bedside and from the laboratory to the vivax research community backed by substantial investments in both basic and applied research.

\section{ACKNOWLEDGMENTS}

I.M. is supported by a National Health and Medical Research Council (NHMRC) Senior Research Fellowship (\#1043345) and J.H.A. is supported by the National Institutes of Health (R01 AI064478). The authors thank Ashley Souza for assistance in preparation of this manuscript.

\section{REFERENCES}

Aikawa M, Miller LH, Rabbege J. 1975. Caveola-vesicle complexes in the plasmalemma of erythrocytes infected by Plasmodium vivax and P. cynomolgi. Unique structures related to Schuffner's dots. Am J Pathol 79: 285-300.

Alves FP, Gil LH, Marrelli MT, Ribolla PE, Camargo EP, Da Silva LH. 2005. Asymptomatic carriers of Plasmodium spp. as infection source for malaria vector mosquitoes in the Brazilian Amazon. J Med Entomol 42: 777-779.

Anstey NM, Douglas NM, Poespoprodjo JR, Price RN. 2012. Plasmodium vivax: Clinical spectrum, risk factors and pathogenesis. Adv Parasitol 80: 151-201.

APLMA. 2014. East Asia Summit adopts unprecedented regional malaria goal. Asia Pacific Leaders Malaria Alliance Secretariat, Mandaluyong City, Philippines.

Arnott A, Mueller I, Ramsland PA, Siba PM, Reeder JC, Barry AE. 2013. Global population structure of the genes encoding the malaria vaccine candidate, Plasmodium vivax apical membrane antigen 1 (PvAMA1). PLoS Negl Trop Dis 7: e2506.
Baird JK. 2013. Evidence and implications of mortality associated with acute Plasmodium vivax malaria. Clin $\mathrm{Mi}$ crobiol Rev 26: 36-57.

Baird K. 2015. Origins and implications of neglect of G6PD deficiency and primaquine toxicity in Plasmodium vivax malaria. Pathog Glob Health 109: 93-106.

Baird JK, Basri H, Purnomo, Bangs MJ, Subianto B, Patchen LC, Hoffman SL. 1991. Resistance to chloroquine by Plasmodium vivax in Irian Jaya, Indonesia. Am J Trop Med Hyg 44: 547-552.

Baird KJ, Maguire JD, Price RN. 2012. Diagnosis and treatment of Plasmodium vivax malaria. Adv Parasitol 80: 203-270.

Barbosa S, Gozze AB, Lima NF, Batista CL, Bastos Mda S, Nicolete VC, Fontoura PS, Goncalves RM, Viana SA, Menezes MJ, et al. 2014. Epidemiology of disappearing Plasmodium vivax malaria: A case study in rural Amazonia. PLoS Negl Trop Dis 8: e3109.

Barry AE, Waltmann A, Koepfli C, Barnadas C, Mueller I. 2015. Uncovering the transmission dynamics of Plasmodium vivax using population genetics. Pathog Glob Health 109: 142-152.

Battle KE, Karhunen MS, Bhatt S, Gething PW, Howes RE, Golding N, Van Boeckel TP, Messina JP, Shanks GD, Smith DL, et al. 2014. Geographical variation in Plasmodium vivax relapse. Malaria J 13: 144.

Betuela I, Rosanas-Urgell A, Kiniboro B, Stanisic DI, Samol L, de Lazzari E, Del Portillo HA, Siba P, Alonso PL, Bassat Q, et al. 2012. Relapses contribute significantly to the risk of Plasmodium vivax infection and disease in Papua New Guinean children 1-5 years of age. J Infect Dis 206: 1771-1780.

Bousema T, Drakeley C. 2011. Epidemiology and infectivity of Plasmodium falciparum and Plasmodium vivax gametocytes in relation to malaria control and elimination. Clin Microbiol Rev 24: 377-410.

Bright AT, Manary MJ, Tewhey R, Arango EM, Wang T, Schork NJ, Yanow SK, Winzeler EA. 2014. A high resolution case study of a patient with recurrent Plasmodium vivax infections shows that relapses were caused by meiotic siblings. PLoS Negl Trop Dis 8: e2882.

Brown KN, Brown IN. 1965. Immunity to malaria: Antigenic variation in chronic infections of Plasmodium knowlesi. Nature 208: $1286-1288$.

Campo B, Vandal O, Wesche DL, Burrows JN. 2015. Killing the hypnozoite-Drug discovery approaches to prevent relapse in Plasmodium vivax. Pathog Glob Health 109: 107-122.

Carvalho BO, Lopes SC, Nogueira PA, Orlandi PP, Bargieri DY, Blanco YC, Mamoni R, Leite JA, Rodrigues MM, Soares IS, et al. 2010. On the cytoadhesion of Plasmodium vivax-infected erythrocytes. J Infect Dis 202: 638647.

Ceravolo IP, Sanchez BA, Sousa TN, Guerra BM, Soares IS, Braga EM, McHenry AM, Adams JH, Brito CF, Carvalho LH. 2009. Naturally acquired inhibitory antibodies to Plasmodium vivax Duffy binding protein are short-lived and allele-specific following a single malaria infection. Clin Exp Immunol 156: 502-510.

Cheng Q, Cunningham J, Gatton ML. 2015. Systematic review of sub-microscopic $P$. vivax infections: Prevalence and determining factors. PLoS Negl Trop Dis 9: e3413. 
Cho JS, Russell B, Kosasaivee V, Zhang R, Colin Y, Bertrand $\mathrm{O}$, Chandramohanadas R, Chu CS, Nosten F, Renia L, et al. 2016. Unambiguous determination of Plasmodium vivax reticulocyte invasion by flow cytometry. Int $\mathrm{J}$ Parasitol 46: 31-39.

Chootong P, Ntumngia FB, VanBuskirk KM, Xainli J, ColeTobian JL, Campbell CO, Fraser TS, King CL, Adams JH. 2010. Mapping epitopes of the Plasmodium vivax Duffy binding protein with naturally acquired inhibitory antibodies. Infect Immun 78: 1089-1095.

Chotivanich K, Udomsangpetch R, Suwanarusk R, Pukrittayakamee S, Wilairatana P, Beeson JG, Day NP, White NJ. 2012. Plasmodium vivax adherence to placental glycosaminoglycans. PLoS ONE 7: e34509.

Coatney GR, Collins WE, Warren M, C PG. 1971. The primate malarias. U.S. Department of Health, Education and Welfare, Washington, DC.

Cole-Tobian JL, Michon P, Biasor M, Richards JS, Beeson JG, Mueller I, King CL. 2009. Strain-specific Duffy binding protein antibodies correlate with protection against infection with homologous compared to heterologous Plasmodium vivax strains in Papua New Guinean children. Infect Immun 77: 4009-4017.

Crosnier C, Bustamante LY, Bartholdson SJ, Bei AK, Theron M, Uchikawa M, Mboup S, Ndir O, Kwiatkowski DP, Duraisingh MT, et al. 2011. Basigin is a receptor essential for erythrocyte invasion by Plasmodium falciparum. $\mathrm{Na}$ ture 480: 534-537.

Delgado-Ratto C, Gamboa D, Soto-Calle VE, Van den Eede P, Torres E, Sanchez-Martinez L, Contreras-Mancilla J, Rosanas-Urgell A, Rodriguez Ferrucci H, LlanosCuentas A, et al. 2016. Population genetics of Plasmodium vivax in the Peruvian Amazon. PLoS Negl Trop Dis 10: e0004376.

del Portillo HA, Fernandez-Becerra C, Bowman S, Oliver K, Preuss M, Sanchez CP, Schneider NK, Villalobos JM, Rajandream MA, Harris D, et al. 2001. A superfamily of variant genes encoded in the subtelomeric region of Plasmodium vivax. Nature 410: 839-842.

Dembele L, Gego A, Zeeman AM, Franetich JF, Silvie O, Rametti A, Le Grand R, Dereuddre-Bosquet N, Sauerwein R, van Gemert GJ, et al. 2011. Towards an in vitro model of Plasmodium hypnozoites suitable for drug discovery. PLoS ONE 6: e18162.

Dembele L, Franetich JF, Lorthiois A, Gego A, Zeeman AM, Kocken CH, Le Grand R, Dereuddre-Bosquet N, van Gemert GJ, Sauerwein R, et al. 2014. Persistence and activation of malaria hypnozoites in long-term primary hepatocyte cultures. Nat Med 20: 307-312.

Douay L, Giarratana MC. 2005. The cultured red blood cell: A study tool with therapeutic perspectives. Cell Cycle 4: 999-1000.

Douglas NM, Simpson JA, Phyo AP, Siswantoro H, Hasugian AR, Kenangalem E, Poespoprodjo JR, Singhasivanon P, Anstey NM, White NJ, et al. 2013. Gametocyte dynamics and the role of drugs in reducing the transmission potential of Plasmodium vivax. J Infect Dis 208: 801812.

Egan ES, Jiang RH, Moechtar MA, Barteneva NS, Weekes MP, Nobre LV, Gygi SP, Paulo JA, Frantzreb C, Tani Y, et al. 2015. Malaria. A forward genetic screen identifies ery- throcyte CD55 as essential for Plasmodium falciparum invasion. Science 348: 711-714.

Fernandez-Becerra C, Pein O, de Oliveira TR, Yamamoto MM, Cassola AC, Rocha C, Soares IS, de Braganca Pereira CA, del Portillo HA. 2005. Variant proteins of Plasmodium vivax are not clonally expressed in natural infections. Mol Microbiol 58: 648-658.

Ferreira MU, Karunaweera ND, da Silva-Nunes M, da Silva NS, Wirth DF, Hartl DL. 2007. Population structure and transmission dynamics of Plasmodium vivax in rural Amazonia. J Infect Dis 195: 1218-1226.

Galinski MR, Barnwell JW. 2008. Plasmodium vivax: Who cares? Malaria J 7: S9.

Getachew S, To S, Trimarsanto H, Thriemer K, Clark TG, Petros B, Aseffa A, Price RN, Auburn S. 2015. Variation in complexity of infection and transmission stability between neighbouring populations of Plasmodium vivax in Southern Ethiopia. PloS ONE 10: e0140780.

Gething PW, Van Boeckel TP, Smith DL, Guerra CA, Patil AP, Snow RW, Hay SI. 2011. Modelling the global constraints of temperature on transmission of Plasmodium falciparum and P. vivax. Parasit Vectors 4: 92.

Gething PW, Elyazar IR, Moyes CL, Smith DL, Battle KE, Guerra CA, Patil AP, Tatem AJ, Howes RE, Myers MF, et al. 2012. A long neglected world malaria map: Plasmodium vivax endemicity in 2010. PLoS Negl Trop Dis 6: e1814.

Giarratana MC, Kobari L, Lapillonne H, Chalmers D, Kiger L, Cynober T, Marden MC, Wajcman H, Douay L. 2005. Ex vivo generation of fully mature human red blood cells from hematopoietic stem cells. Nat Biotechnol 23: 69-74.

Golenda CF, Li J, Rosenberg R. 1997. Continuous in vitro propagation of the malaria parasite Plasmodium vivax. Proc Natl Acad Sci 94: 6786-6791.

Handayani S, Chiu DT, Tjitra E, Kuo JS, Lampah D, Kenangalem E, Renia L, Snounou G, Price RN, Anstey NM, et al. 2009. High deformability of Plasmodium vivax-infected red blood cells under microfluidic conditions. J Infect Dis 199: $445-450$.

Hemmer CJ, Holst FG, Kern P, Chiwakata CB, Dietrich M, Reisinger EC. 2006. Stronger host response per parasitized erythrocyte in Plasmodium vivax or ovale than in Plasmodium falciparum malaria. Trop Med Int Health 11: 817-823.

Hupalo DN, Luo Z, Melnikov A, Sutton PL, Rogov P, Escalante A, Vallejo AF, Herrera S, Arévalo-Herrera M, Fan Q, et al. 2016. Population genomics reveals signatures of global dispersal and drug resistance in Plasmodium vivax. Nat Genet 48: 953-958.

Imwong M, Nair S, Pukrittayakamee S, Sudimack D, Williams JT, Mayxay M, Newton PN, Kim JR, Nandy A, Osorio L, et al. 2007. Contrasting genetic structure in Plasmodium vivax populations from Asia and South America. Int J Parasitol 37: 1013-1022.

Jemmely NY, Niang M, Preiser PR. 2010. Small variant surface antigens and Plasmodium evasion of immunity. Future Microbiol 5: 663-682.

Jennison C, Arnott A, Tessier N, Tavul L, Koepfli C, Felger I, Siba PM, Reeder JC, Bahlo M, Mueller I, et al. 2015. Plasmodium vivax populations are more genetical- 
J.H. Adams and I. Mueller

ly diverse and less structured than sympatric Plasmodium falciparum populations. PLoS Negl Trop Dis 9: e0003634.

Ketema T, Bacha K, Birhanu T, Petros B. 2009. Chloroquineresistant Plasmodium vivax malaria in Serbo town, Jimma zone, south-west Ethiopia. Malaria J 8: 177.

Koepfli C, Colborn KL, Kiniboro B, Lin E, Speed TP, Siba PM, Felger I, Mueller I. 2013. A high force of Plasmodium vivax blood-stage infection drives the rapid acquisition of immunity in Papua New Guinean children. PLoS Negl Trop Dis 7: e2403.

Koepfli C, Robinson LJ, Rarau P, Salib M, Sambale N, Wampfler R, Betuela I, Nuitragool W, Barry AE, Siba P, et al. 2015a. Blood-stage parasitaemia and age determine Plasmodium falciparum and P. vivax gametocytaemia in Papua New Guinea. PLoS ONE 10: e0126747.

Koepfli C, Rodrigues PT, Antao T, Orjuela-Sanchez P, Van den Eede P, Gamboa D, van Hong N, Bendezu J, Erhart A, Barnadas C, et al. 2015b. Plasmodium vivax diversity and population structure across four continents. PLoS Negl Trop Dis 9: e0003872.

Krotoski WA, Collins WE, Bray RS, Garnham PC, Cogswell FB, Gwadz RW, Killick-Kendrick R, Wolf R, Sinden R, Koontz LC, et al. 1982. Demonstration of hypnozoites in sporozoite-transmitted Plasmodium vivax infection. Am J Trop Med Hyg 31: 1291-1293.

Kumar AA, Lim C, Moreno Y, Mace CR, Syed A, Van Tyne D, Wirth DF, Duraisingh MT, Whitesides GM. 2015. Enrichment of reticulocytes from whole blood using aqueous multiphase systems of polymers. Am J Hematol 90: 3136.

Lee WC, Malleret B, Lau YL, Mauduit M, Fong MY, Cho JS, Suwanarusk R, Zhang R, Albrecht L, Costa FT, et al. 2014. Glycophorin C (CD236R) mediates vivax malaria parasite rosetting to normocytes. Blood 123: e100-109.

Lin E, Kiniboro B, Gray L, Dobbie S, Robinson L, Laumea A, Schoepflin S, Lori L, Betuela I, Siba P, et al. 2010. Differential patterns of infection and disease with $P$. falciparum and $P$. vivax in young Papua New Guinean children. PloS ONE 5: e9047.

Liu W, Li Y, Shaw KS, Learn GH, Plenderleith LJ, Malenke JA, Sundararaman SA, Ramirez MA, Crystal PA, Smith AG, et al. 2014. African origin of the malaria parasite Plasmodium vivax. Nat Commun 5: 3346.

Maher SP, Crouse RB, Conway AJ, Bannister EC, Achyuta AK, Clark AY, Sinatra FL, Cuiff JD, Adams JH, Kyle DE, et al. 2014. Microphysical space of a liver sinusoid device enables simplified long-term maintenance of chimeric mouse-expanded human hepatocytes. Biomed Microdevices 16: 727-736.

Maitland K, Williams TN, Bennett S, Newbold CI, Peto TE, Viji J, Timothy R, Clegg JB, Weatherall DJ, Bowden DK. 1996. The interaction between Plasmodium falciparum and $P$. vivax in children on Espiritu Santo island, Vanuatu. Trans R Soc Trop Med Hyg 90: 614-620.

Malleret B, Li A, Zhang R, Tan KS, Suwanarusk R, Claser C, Cho JS, Koh EG, Chu CS, Pukrittayakamee S, et al. 2015 Plasmodium vivax: Restricted tropism and rapid remodeling of CD71-positive reticulocytes. Blood 125: 13141324.
March S, Ng S, Velmurugan S, Galstian A, Shan J, Logan DJ, Carpenter AE, Thomas D, Sim BK, Mota MM, et al. 2013. A microscale human liver platform that supports the hepatic stages of Plasmodium falciparum and vivax. Cell Host Microbe 14: 104-115.

Marfurt J, Chalfein F, Prayoga P, Wabiser F, Wirjanata G, Sebayang B, Piera KA, Wittlin S, Haynes RK, Mohrle JJ, et al. 2012. Comparative ex vivo activity of novel endoperoxides in multidrug-resistant Plasmodium falciparum and P. vivax. Antimicrob Agents Chemother 56: 52585263.

Martin-Jaular L, Elizalde-Torrent A, Thomson-Luque R, Ferrer M, Segovia JC, Herreros-Aviles E, FernandezBecerra C, Del Portillo HA. 2013. Reticulocyte-prone malaria parasites predominantly invade CD71hi immature cells: Implications for the development of an in vitro culture for Plasmodium vivax. Malaria J 12: 434.

Mazier D, Landau I, Druilhe P, Miltgen F, Guguen-Guillouzo C, Baccam D, Baxter J, Chigot JP, Gentilini M. 1984. Cultivation of the liver forms of Plasmodium vivax in human hepatocytes. Nature 307: 367-369.

Mendis K, Sina BJ, Marchesini P, Carter R. 2001a. The neglected burden of Plasmodium vivax malaria. Am J Trop Med Hyg 64: 97-106.

Mendis K, Sina BJ, Mechesini P, Carter R. 2001b. The neglected burden of Plasmodium vivax malaria. Am J Trop Med Hyg 64: 97-106.

Michon P, Cole-Tobian JL, Dabod E, Schoepflin S, Igu J, Susapu M, Tarongka N, Zimmerman PA, Reeder JC, Beeson JG, et al. 2007. The risk of malarial infections and disease in Papua New Guinean children. Am J Trop Med Hyg 76: 997-1008.

Mikolajczak SA, Vaughan AM, Kangwanrangsan N, Roobsoong W, Fishbaugher M, Yimamnuaychok N, Rezakhan N, Lakshmanan V, Singh N, Kaushansky A, et al. 2015. Plasmodium vivax liver stage development and hypnozoite persistence in human liver-chimeric mice. Cell Host Microbe 17: 526-535.

Mohan K, Maithani MM. 2010. Congenital malaria due to chloroquine-resistant Plasmodium vivax: A case report. Trop Pediatr 56: 454-455.

Mueller I, Galinski MR, Baird JK, Carlton JM, Kochar DK, Alonso PL, del Portillo HA. 2009. Key gaps in the knowledge of Plasmodium vivax, a neglected human malaria parasite. Lancet Infect Dis 9: 555-566.

Mueller I, Galinski MR, Tsuboi T, Arevalo-Herrera M, Collins WE, King CL. 2013. Natural acquisition of immunity to Plasmodium vivax: Epidemiological observations and potential targets. Adv Parasitol 81: 77-131.

Mueller I, Shakri AR, Chitnis CE. 2015. Development of vaccines for Plasmodium vivax malaria. Vaccine 33: 7489-7495.

Neafsey DE, Galinsky K, Jiang RH, Young L, Sykes SM, Saif S, Gujja S, Goldberg JM, Young S, Zeng Q, et al. 2012. The malaria parasite Plasmodium vivax exhibits greater genetic diversity than Plasmodium falciparum. Nat Genet 44: 1046-1050.

Ng S, Schwartz RE, March S, Galstian A, Gural N, Shan J, Prabhu M, Mota MM, Bhatia SN. 2015. Human iPSCderived hepatocyte-like cells support Plasmodium liverstage infection in vitro. Stem Cell Rep 4: 348-359. 
Noulin F, Borlon C, Van Den Abbeele J, D’Alessandro U, Erhart A. 2013. 1912-2012: A century of research on Plasmodium vivax in vitro culture. Trends Parasitol 29: 286-294.

Noulin F, Manesia JK, Rosanas-Urgell A, Erhart A, Borlon C, Van Den Abbeele J, d'Alessandro U, Verfaillie CM. 2014. Hematopoietic stem/progenitor cell sources to generate reticulocytes for Plasmodium vivax culture. PLOS ONE 9: el12496.

Noviyanti R, Coutrier F, Utami RA, Trimarsanto H, Tirta YK, Trianty L, Kusuma A, Sutanto I, Kosasih A, Kusriastuti R, et al. 2015. Contrasting transmission dynamics of co-endemic Plasmodium vivax and P. falciparum: Implications for malaria control and elimination. PLoS Negl Trop Dis 9: e0003739.

PAHO. 2013. Central America and Hispaniola seek to eliminate malaria by 2025. Pan American Health Organization, Geneva.

Panichakul T, Sattabongkot J, Chotivanich K, Sirichaisinthop J, Cui L, Udomsangpetch R. 2007. Production of erythropoietic cells in vitro for continuous culture of Plasmodium vivax. Int J Parasitol 37: 1551-1557.

Pearson RD, Amato R, Auburn S, Miotto O, Almagro-Garcia J, Amaratunga C, Seila S, Mao S, Noviyanti R, Trimarsanto H, et al. 2016. Genomic analysis of local variation and recent evolution in the Plasmodium vivax population. Nat Genet 48: 959-964.

Peltz G. 2013. Can "humanized" mice improve drug development in the 21st century? Trends Pharmacol Sci 34: 255-260.

Pethleart A, Prajakwong S, Suwonkerd W, Corthong B, Webber R, Curtis C. 2004. Infectious reservoir of Plasmodium infection in Mae Hong Son Province, north-west Thailand. Malaria J 3: 34.

Phimpraphi W, Paul RE, Yimsamran S, Puangsa-art S, Thanyavanich N, Maneeboonyang W, Prommongkol S, Sornklom S, Chaimungkun W, Chavez IF, et al. 2008. Longitudinal study of Plasmodium falciparum and Plasmodium vivax in a Karen population in Thailand. $\mathrm{Ma}$ laria J 7: 99.

Price RN, Tjitra E, Guerra CA, Yeung S, White NJ, Anstey NM. 2007. Vivax malaria: Neglected and not benign. $A m$ J Trop Med Hyg 77: 79-87.

Price RN, Marfurt J, Chalfein F, Kenangalem E, Piera KA, Tjitra E, Anstey NM, Russell B. 2010. In vitro activity of pyronaridine against multidrug-resistant Plasmodium falciparum and Plasmodium vivax. Antimicrob Agents Chemother 54: 5146-5150.

Rijken MJ, Boel ME, Russell B, Imwong M, Leimanis ML, Pyae Phyo A, Muehlenbachs A, Lindegardh N, McGready $\mathrm{R}$, Renia L, et al. 2011. Chloroquine resistant vivax malaria in a pregnant woman on the western border of Thailand. Malaria J 10: 113.

Robinson LJ, Wampfler R, Betuela I, Karl S, White MT, Li Wai Suen CS, Hofmann NE, Kinboro B, Waltmann A, Brewster J, et al. 2015. Strategies for understanding and reducing the Plasmodium vivax and Plasmodium ovale hypnozoite reservoir in Papua New Guinean children: A randomised placebo-controlled trial and mathematical model. PLoS Med 12: e1001891.

Roobsoong W, Tharinjaroen CS, Rachaphaew N, Chobson P, Schofield L, Cui L, Adams JH, Sattabongkot J. 2015. Im- provement of culture conditions for long-term in vitro culture of Plasmodium vivax. Malaria J 14: 297.

Ruebush TK 2nd, Zegarra J, Cairo J, Andersen EM, Green M, Pillai DR, Marquino W, Huilca M, Arevalo E, Garcia C, et al. 2003. Chloroquine-resistant Plasmodium vivax malaria in Peru. Am J Trop Med Hyg 69: 548-552.

Russell B, Suwanarusk R, Borlon C, Costa FT, Chu CS, Rijken MJ, Sriprawat K, Warter L, Koh EG, Malleret B, et al. 2011. A reliable ex vivo invasion assay of human reticulocytes by Plasmodium vivax. Blood 118: e74-e81.

Sattabongkot J, Yimamnuaychoke N, Leelaudomlipi S, Rasameesoraj M, Jenwithisuk R, Coleman RE, Udomsangpetch R, Cui L, Brewer TG. 2006. Establishment of a human hepatocyte line that supports in vitro development of the exo-erythrocytic stages of the malaria parasites Plasmodium falciparum and P. vivax. Am J Trop Med Hyg 74: 708-715.

Shultz LD, Ishikawa F, Greiner DL. 2007. Humanized mice in translational biomedical research. Nat Rev Immunol 7: $118-130$.

Snounou G, Perignon JL. 2013. Malariotherapy-Insanity at the service of malariology. Adv Parasitol 81: 223-255.

Soulard V, Bosson-Vanga H, Lorthiois A, Roucher C, Franetich JF, Zanghi G, Bordessoulles M, Tefit M, Thellier M, Morosan S, et al. 2015. Plasmodium falciparum full life cycle and Plasmodium ovale liver stages in humanized mice. Nat Commun 6: 7690.

Suwanarusk R, Cooke BM, Dondorp AM, Silamut K, Sattabongkot J, White NJ, Udomsangpetch R. 2004. The deformability of red blood cells parasitized by Plasmodium falciparum and P. vivax. J Infect Dis 189: 190-194.

Teka H, Petros B, Yamuah L, Tesfaye G, Elhassan I, Muchohi S, Kokwaro G, Aseffa A, Engers H. 2008. Chloroquineresistant Plasmodium vivax malaria in Debre Zeit, Ethiopia. Malaria J 7: 220.

Udagama PV, Atkinson CT, Peiris JS, David PH, Mendis KN, Aikawa M. 1988. Immunoelectron microscopy of Schuffner's dots in Plasmodium vivax-infected human erythrocytes. Am J Pathol 131: 48-52.

Udomsangpetch R, Somsri S, Panichakul T, Chotivanich K, Sirichaisinthop J, Yang Z, Cui L, Sattabongkot J. 2007. Short-term in vitro culture of field isolates of Plasmodium vivax using umbilical cord blood. Parasitol Int 56: $65-69$.

Vallejo AF, Garcia J, Amado-Garavito AB, Arevalo-Herrera M, Herrera S. 2016. Plasmodium vivax gametocyte infectivity in sub-microscopic infections. Malaria J 15: 48.

VanBuskirk KM, Cole-Tobian JL, Baisor M, Sevova ES, Bockarie M, King CL, Adams JH. 2004. Antigenic drift in the ligand domain of Plasmodium vivax Duffy binding protein confers resistance to inhibitory antibodies. J Infect Dis 190: 1556-1562.

Van den Eede P, Van der Auwera G, Delgado C, Huyse T, Soto-Calle VE, Gamboa D, Grande T, Rodriguez H, Llanos A, Anne J, et al. 2010. Multilocus genotyping reveals high heterogeneity and strong local population structure of the Plasmodium vivax population in the Peruvian Amazon. Malaria J 9: 151.

Wampfler R, Mwingira F, Javati S, Robinson L, Betuela I, Siba P, Beck HP, Mueller I, Felger I. 2013. Strategies for 
J.H. Adams and I. Mueller

detection of Plasmodium species gametocytes. PLoS ONE 8: e76316.

Wells TN, Burrows JN, Baird JK. 2010. Targeting the hypnozoite reservoir of Plasmodium vivax: The hidden obstacle to malaria elimination. Trends Parasitol 26: 145151.

White NJ. 2011. Determinants of relapse periodicity in Plasmodium vivax malaria. Malaria J 10: 297.
White NJ, Imwong M. 2012. Relapse. Adv Parasitol 80: $113-$ 150.

White M, Shirreff G, Karl S, Ghani A, Mueller I. 2016. Variation in relapse frequency and the transmission potential of Plasmodium vivax malaria. Proc Biol Sci 283: 20160048.

WHO. 2015. World malaria report 2015. Global malaria programme. World Health Organization, Geneva. 


\section{$\&_{\mathrm{CSH}}^{\infty} \&$ Cold Spring Harbor

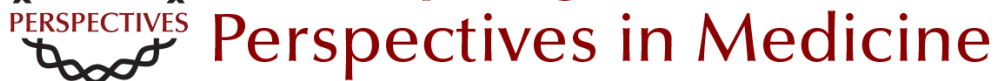

\section{The Biology of Plasmodium vivax}

John H. Adams and Ivo Mueller

Cold Spring Harb Perspect Med 2017; doi: 10.1101/cshperspect.a025585 originally published online May 10, 2017

\section{Subject Collection Malaria: Biology in the Era of Eradication}

Modern Vector Control

Neil F. Lobo, Nicole L. Achee, John Greico, et al.

Anopheline Reproductive Biology: Impacts on Vectorial Capacity and Potential Avenues for

Malaria Control Sara N. Mitchell and Flaminia Catteruccia

Current and Future Prospects for Preventing Malaria Transmission via the Use of Insecticides Hilary Ranson

Molecular Signaling Involved in Entry and Exit of Malaria Parasites from Host Erythrocytes Shailja Singh and Chetan E. Chitnis

Vaccines to Accelerate Malaria Elimination and Eventual Eradication Julie Healer, Alan F. Cowman, David C. Kaslow, et al.

Immune Responses in Malaria Carole A. Long and Fidel Zavala

Antimalarial Drug Resistance: A Threat to Malaria Elimination Didier Menard and Arjen Dondorp

Malaria during Pregnancy Michal Fried and Patrick E. Duffy
Malaria Pathogenesis Danny A. Milner, Jr.

Determinants of Malaria Transmission at the Population Level Teun Bousema and Chris Drakeley

\section{Host Cell Tropism and Adaptation of Blood-Stage Malaria Parasites: Challenges for Malaria \\ Elimination Caeul Lim, Selasi Dankwa, Aditya S. Paul, et al.}

Malaria Transmission and Prospects for Malaria Eradication: The Role of the Environment Marcia C. Castro

The Biology of Plasmodium vivax John H. Adams and Ivo Mueller

Malaria Genomics in the Era of Eradication Daniel E. Neafsey and Sarah K. Volkman

Malaria Epigenetics Alfred Cortés and Kirk W. Deitsch

Malaria Parasite Liver Infection and Exoerythrocytic Biology Ashley M. Vaughan and Stefan H.I. Kappe

For additional articles in this collection, see http://perspectivesinmedicine.cshlp.org/cgi/collection/ 